\title{
Percutaneous Radiofrequency Thermocoagulation in Tri- geminal Neuralgia : Analysis of Early and Late Outcomes of 156 Cases and 209 Interventions
}

\author{
Hasan Burak Gunduz, Orhun Mete Cevik, Murad Asilturk, Muslum Gunes, Mustafa Levent Uysal, Ozden Erhan Sofuoglu, \\ Erhan Emel \\ Department of Neurosurgery, Bakirkoy Prof. Dr. Mazhar Osman Training and Research Hospital for Neurology, Neurosurgery and Psychiatry. \\ Istanbul, Turkey
}

Objective : Trigeminal neuralgia is one of the most common causes of facial pain. Our aim is to investigate the efficacy and borders of percutaneous radiofrequency thermocoagulation in the treatment of trigeminal neuralgia.

Methods : Between May 2007 and April 2017, 156 patients with trigeminal neuralgia were treated with radiofrequency thermocoagulation. These 156 patients underwent 209 procedures. In our study, we investigated the early and late results of percutaneous radiofrequency thermocoagulation under guiding fluoroscopic imaging in the treatment of trigeminal neuralgia. Barrow Neurological Institute (BNI) pain scale was used for grading the early results. In addition, Kaplan-Meier survival analysis was used to assess long-term outcomes. Of the 156 patients who underwent radiofrequency thermocoagulation for trigeminal neuralgia, 45 had additional disease. Patients with this condition were evaluated with their comorbidities. Early and late results were compared with those without comorbidity.

Results : In 193 of 209 interventions BNI pain scale I to III results were obtained. Out of the 193 successful operation 136 patients (65.07\%) were discharged as BNI I, 14 (6.70\%) as BNI II, 43 (20.58\%) as BNI III. Sixteen patients (7.65\%) remained uncontrolled (BNI IV and $\mathrm{V}$ ). While the treatment results of trigeminal neuralgia patients with comorbidity seem more successful in the early period, this difference was not observed in follow-up examinations.

Conclusion : Finally, we concluded that percutaneous radiofrequency thermocoagulation of the Gasserian ganglion is a safe and effective method in the treatment of trigeminal neuralgia. However, over time, the effectiveness of the treatment decreases. Neverthless, the reapprability of this intervention gives it a distinct advantage.

Key Words : Facial pain · Foramen ovale · Radiofrequency ablation · Trigeminal neuralgia.

\section{INTRODUCTION}

Trigeminal neuralgia (TN) is the most common of all cra- nial neuralgias. According to the 3rd edition of the International Classification of Headache Disorders, TN is a disorder characterized by recurrent unilateral brief electric shock-like

- Received : December 2, 2020 •Revised : January 4, 2021 •Accepted : January 27, 2021

- Address for reprints : Hasan Burak Gunduz

Department of Neurosurgery, Bakirkoy Prof. Dr. Mazhar Osman Ruh Sagligi ve Sinir Hastaliklari Egitim ve Arastirma Hastanesi, Zuhuratbaba Mahallesi, Dr. Tevfik Saglam Cad 25/2, Bakirkoy/lstanbul 34147, Turkey

Tel : +905325733120, E-mail : bgunduz62@yahoo.com, ORCID : https://orcid.org/0000-0003-0020-7928

This is an Open Access article distributed under the terms of the Creative Commons Attribution Non-Commercial License (http://creativecommons.org/licenses/by-nc/4.0) which permits unrestricted non-commercial use, distribution, and reproduction in any medium, provided the original work is properly cited. 
pains, abrupt in onset and termination, limited to the distribution of one or more divisions of the trigeminal nerve and triggered by innocuous stimuli. It may develop without apparent cause or be a result of another diagnosed disorder ${ }^{19,39)}$. Currently, the pathophysiology of TN remains unclear. According to the "ignition theory" TN is the result of abnormalities in the afferent neurons of the trigeminal root or ganglion". The incidence of TN is two to five patients per 100000 people $\mathrm{e}^{6,8,15,20,35)}$.

Today, there are three major theories explaining the etiology of TN. The first is related to the disease (multiple sclerosis [MS], diabetes mellitus, hypertension) the other to the direct trauma to the nerve (neurovascular compression), and the third to the polyetiological origin of the disease. In selected cases, decompression of the vascular structure that presses on the fifth nerve has been shown to relieve pain ${ }^{12,13,33)}$. Additionally, The third factor can be explained as all possible aetiological factors that can affect the trigeminal nerve system and evoke demyelination and dystrophy. In spite of all these, no identifiable cause can be found for most TN patients ${ }^{25,36)}$.

There are many medical and surgical options available for the treatment of TN. Currently, many disciplines of clinical and basic sciences continue to investigate etiological factors and the most effective treatment methods for TN. In this article we investigated early and late results of TN which has been treated with radiofrequency thermocoagulation (RFT). We recorded the complications encountered during this period. We further searched into the relations between TN and accompanying diseases.

\section{Treatment}

The first step in TN treatment is the conservative medical treatment ${ }^{18)}$. Initially, the response to medical therapy is $80 \%$, which decrease to less than $50 \%$ over time ${ }^{10)}$. In cases where medical treatment is ineffective or associated with significant side effects, surgical treatment options may be considered. These options include percutaneous glycerol rhizotomy, radiofrequency rhizotomy, balloon compression, peripheral nerve section, radiosurgery and microvascular decompression $(\mathrm{MVD})^{18)}$.

The foramen ovale puncture was first described by Härtel ${ }^{9)}$ in 1913 as a percutaneous route to the Meckel Cave to treat $\mathrm{TN}^{11,21,24)}$. In 1974, Sweet and Wepsic ${ }^{29)}$ introduced radio frequency generated thermal energy to damage the preganglion- ic trigeminal rootlets in the Meckel cave. Under appropriate conditions, percutaneous RFT is a viable treatment method because of the short application time, long effect time, the possibility of a reintervention and high patient satisfaction $\operatorname{rate}^{2,22,27,30-32,37)}$.

\section{MATERIALS AND METHODS}

\section{Patient selection}

Ethics Committee approval was obtained for this study (Date : December 1, 2016; approval document number : 514).

First of all, we preferred to include the patients who can be defined as typical TN into the RFT procedure. This group consisted of patients with pain on the face characterized by paroxysmal lancing, shocklike pain confined to the somatosensory distribution of the trigeminal nerve ${ }^{14)}$. We excluded TN cases with atypical features outside the RF group.

Cranial magnetic resonance (MR) imaging was performed in all patients who underwent intervention. RFT was recommended for patients who did not have an image of vascular compression. In addition, RFT was recommended for MS patients and patients who cannot be administered general anesthesia due to their comorbidities. In addition, during this period, MVD surgery was performed on 67 patients who were found to have significant vascular compression on the Trigeminal Nerve on MR imagination.

A total of 209 procedures were done in 156 patients between May 2007 and April 2017 in a single Neurosurgery clinic and the results were retrospectively analyzed. Patient profiles, the immediate outcome of the therapy, painless time margin, and complications were obtained from the hospital medical records, clinical follow-ups and questionnaires sent to patients

Table 1. Barrow Neurological Institute pain intensity scale

\begin{tabular}{ll}
\hline Pain score & \multicolumn{1}{c}{ Definition } \\
\hline I & No trigeminal pain, no medication \\
III & Occasional pain, not requiring medication \\
& Some pain, adequately controlled with medication \\
& - IIla : No pain, continued medication \\
IV & -IIlb : Persistent pain, controlled with medication \\
V & Some pain, not adequately controlled wit medication \\
\hline
\end{tabular}


after April 2017. Postoperative results of patients were graded using the Barrow Neurological Institute (BNI) pain scale $(\text { Table } 1)^{4)}$. For assessing long term outcomes Kaplan-Meier survival analysis was used ${ }^{7)}$.

The study group consisted of 81 female (52.94\%) and 75 male $(47.06 \%)$ patients. The ages ranged between $27-86$ where the average was $58.03 \pm 14$. One hundred patients $(64.10 \%)$ had right, 56 (35.90\%) had left sided symptoms. The branches involved were isolated V1 in one patient $(0.48 \%)$, isolated V2 in 57 patients (27.27\%), isolated V3 in 40 patients (19.14\%), V1 and $\mathrm{V} 2$ in 17 patients (8.13\%), V2 and V3 in 70 patients (33.50\%), and V1, V2 and V3 in 24 patients (11.48\%) (Table 2).

\section{Surgical course}

The patient is taken to the operating table in supine position. Fluoroscopy is adjusted to show the cella turcica, clivus and petrous apex on the lateral image. The position is confirmed by seeing the aligned orbital roofs and anterior clinoid processes.

Härtel $^{9)}$ anatomical landmarks are used for percutaneous procedures to the Gasserian Ganglion. The entry point is 2.5 $\mathrm{cm}$ lateral to the angle of the mouth. An 18-gauge needle cannula is inserted along the medial of the coronoid process of the mandible and aimed toward the plane intersecting a point 30 $\mathrm{mm}$ anterior to the external acoustic meatus along the zygo-

Table 2. Demographics of patients and localization of pain with trigeminal neuralgia treated with percutaneous radiofrequency thermocoagulation

\begin{tabular}{lc}
\hline Characteristic & Value \\
\hline Patients ( $\mathrm{n}=156)$ & \\
Age (years) & $58.03 \pm 14.01(27-86)$ \\
Sex, $\mathrm{F}: \mathrm{M}$ & $81(52.94): 75(47.06)$ \\
Affected side, R: L & $100(64.10): 56(34.90)$ \\
Procedures (n=209) & \\
Affected division (all interventions) & $1(0.48)$ \\
V1 & $57(27.27)$ \\
V2 & $40(19.14)$ \\
V3 & $17(8.13)$ \\
V1, V2 & $70(33.50)$ \\
V2, V3 & $24(11.48)$ \\
V1, V2, V3 &
\end{tabular}

Values are presented as mean \pm standard deviation (range) or number (\%) $F$ : female, $M$ : male, $R$ : right, $L$ : left matic arch and the medial aspect of the pupil. A free-hand technique is then used to direct the needle toward the foramen ovale with a finger inside the oral cavity to prevent perforation of the ipsilateral buccal mucosa and to ensure that the needle traveled medial to the mandible. The imaging of the needle during the procedure is performed by lateral image fluoroscopy. In 32 (15.31\%) of 209 interventions, we added oblique submental imaging in addition to lateral imaging (Fig. 1).

After foramen ovale is penetrated at the correct position, cerebrospinal fluid can be observed at the proximal end of the needle. Although this can be accepted as a sign of Meckel Cave penetration, following deciding that we have placed the electrode properly, we give motor and sensory stimuli. Then the RF device is switched to the stimulus mode and a low frequency stimulus (2 Mhz) is applied. If the masticatory response is observed when the stimulus is applied, the frequency is increased as the second step (75 Mhz). When re-stimulation is applied pain that mimics neuralgia is expected. The final localization of the needle is decided with the help of the character and localization of the pain produced by the radiofrequency generator supplied stimulation. Ineffective results of the stimulation point towards misplacement. Depending on the patient's response, a new position is given to the electrode. Additionally, pain around the eye on stimulation also points to a misplacement of the needle to a V1 zone. Lesion generation close to the V1 branch should be avoided due to increased risk of keratitis. After confirming the localization, three radiofrequency lesions are performed at $70^{\circ} \mathrm{C}$ each in $3-5 \mathrm{~mm}$. After each replacement of the electrode, the accuracy of the position is checked by applying stimulation. In addition, corneal reflex control should be performed at each stage of the intervention.

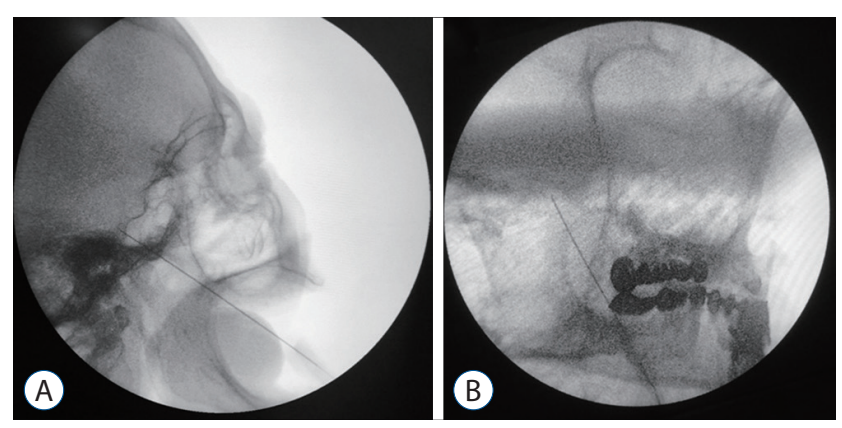

Fig. 1. Trajectory of the catheter needle in lateral (A) and oblique submental (B) cranial radiograph images. 
Table 3. Early RFT results according to the BNI scale

\begin{tabular}{lc}
\hline BNI pain score & Value $(\mathbf{n = 2 0 9 )}$ \\
\hline I & $136(65.07)$ \\
II & $14(6.70)$ \\
III & $43(20.58)$ \\
IIIb & $29(13.88)$ \\
IV & $14(6.70)$ \\
V & $13(6.22)$ \\
\hline
\end{tabular}

Values are presented as number (\%). RFT : radiofrequency thermocoagulation, BNI : Barrow Neurological Institute

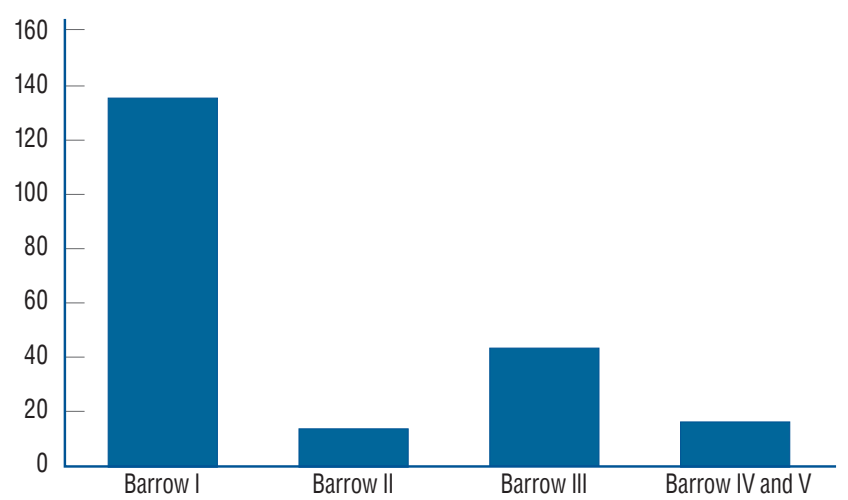

Fig. 2. Early period results according to Barrow Neurological Institute pain intensity scale.

\section{RESULTS}

\section{Early period results}

A total of 209 procedures were done in 156 patients. BNI pain scale was used for grading the early results. One hundred ninety-three procedures out of 209 have achieved BNI I to III on early postoperative period. Out of the 193 successfully operated patients 136 patients $(65.07 \%)$ were discharged as BNI I, $14(6.70 \%)$ as BNI II and $43(20.58 \%)$ as BNI III. Of the 43 patients, 29 (13.88\%) were BNI IIIa and 14 were BNI IIIb (6.70\%). Over 209 procedures, 16 patients (7.65\%) remained uncontrolled (BNI IV and V) (Table 3 and Fig. 2).

\section{Follow-up}

The number of patients in the follow-up was decreased over time. In the 1 year follow up, 156 patients were in control out of the 174 patients. After the Kaplan-Meier analysis, both the controlled pain rate and the cumulative control rate of the group are $89.66 \%$. In the 3 rd year follow up, 81 out of the 130 eligible patients were in control. According to the KaplanMeier analysis the pain control rate is $62.3 \%$ and the cumulative control rate is $55.86 \%$. For the 5 th year follow up 29 out of the 81 eligible patients remained under control, which gave a controlled pain rate of $35.8 \%$ and a cumulative rate of $20 \%$ (Fig. 3). On the April 2016 follow up of the study, the longest controlled pain patient had 118 months of painless period.

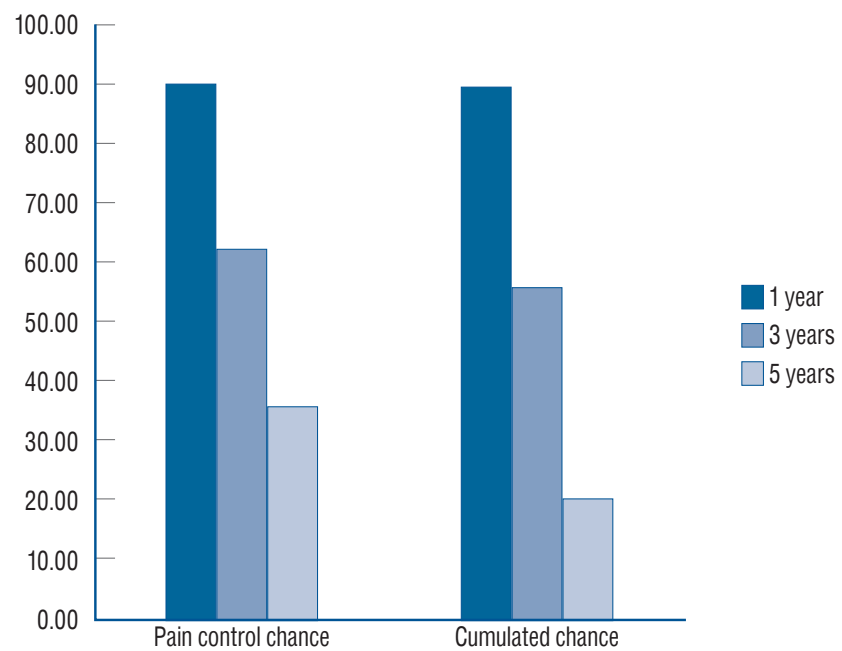

Fig. 3. A graph showing Kaplan-Meier analysis of the pain-free survival rate of 209 surgical procedures with trigeminal neuralgia treated by radiofrequency thermocoagulation. $X$-axis denotes pain-free survival in years and $y$-axis denotes cumulative survival. 


\section{Complications}

In the postoperative period moderate intrabuccal hematoma was observed in 19 patients (9.10\%). Varying postoperative hypoesthesia has been seen almost on all effective interventions. Hypoesthesia on the region is not interpreted as a complication by the surgical team. It was the expected result of Gasserian ganglion blockage. Detailed information was given to the patients before the procedures. One hundred ninetythree out of 209 procedures had facial hypoesthesia. The degree of hypoesthesia ranged from tactile hypoesthesia $(n=182$, $87.08 \%$ ) to facial numbness ( $n=11,5.26 \%$ ). The early results of 193 patients who developed facial hypoesthesia after RF treatment were evaluated as BNI I in 136 (65.07\%), BNI II in 14 (6.70\%), and BNI III in 43 patients (20.57\%).

In 13 patients $(6.22 \%)$, sensory changes were uncertain. In patients whose sensory changes were uncertain, early BNI results were grade IV in eight patients (3.83\%), grade $\mathrm{V}$ in five patients $(2.39 \%)$. In addition to these sensory changes, dysesthesia was observed in three patients (1.43\%). These three patients were in BNI V group (Table 4). Results showed a lower rate of early pain remission in patients without sensory changes.

Masseter muscle weakness and temporal muscle atrophy have been seen on five patients (2.39\%) and one patient $(0.48 \%)$, respectively. Corneal hypoesthesia have been seen on

Table 4. Sensory changes after RFT in early period

\begin{tabular}{cc}
\hline & $\begin{array}{c}\text { Sensory changes in all procedures } \\
(\mathbf{n}=\mathbf{2 0 9})\end{array}$ \\
\hline Facial hypoesthesia & $193(92.34)$ \\
Tactile hypoesthesia & $182(87.08)$ \\
BNI I & $127(60.77)$ \\
BNI II & $13(6.22)$ \\
BNI III & $42(20.10)$ \\
Facial numbness & $11(5.26)$ \\
BNI I & $9(4.31)$ \\
BNI II & $1(0.48)$ \\
BNI III & $1(0.48)$ \\
No sensory change & $13(6.22)$ \\
BNI IV & $8(3.83)$ \\
BNI V & $5(2.39)$ \\
Dysesthesia & $3(1.43)$ \\
BNI V & $3(1.43)$ \\
\hline
\end{tabular}

Values are presented as number (\%). RFT : radiofrequency thermocoagulation, BNI : Barrow Neurological Institute six patients and one patient had corneal reflex deficit (3.35\%). Artificial tear drop has been prescribed to the seven patients. In the long term no keratitis has been observed in these patients (Table 5).

\section{DISCUSSION}

We analyzed our patients for pain relief, early and persistent complications, painless period and repeat interventions, and accompanying diseases.

\section{Analysis of treatment and results}

One hundred ninety-three (92.34\%) of the 209 surgeries were in the first three scoring according to the BNI pain intensity score. Score I was a complete painless result and did not require additional medical support (136, 65.07\%). There

Table 5. Complications occured due to intervention in 209 procedures

\begin{tabular}{lc}
\hline Complication & Procedure $(\mathbf{n = 2 0 9 )}$ \\
\hline Intrabuccal hematoma & $19(9.10)$ \\
Corneal hypoesthesia and reflex deficit & $7(3.35)$ \\
Dysesthesia & $3(1.43)$ \\
Masseter muscle weakness & $5(2.39)$ \\
Atrophy of temporal muscle & $1(0.48)$ \\
\hline
\end{tabular}

Values are presented as number (\%)

Table 6. Trigeminal neuralgia and comorbidities

\begin{tabular}{lc}
\hline & Value \\
\hline CVS, HT & 23 \\
Multiple sclerosis & 5 \\
DM & 3 \\
Thyroid diseases & 3 \\
Respiratory system diseases & 2 \\
Glaucoma & 1 \\
Gastrointestinal diseases & 1 \\
Coexisting diseases & \\
HT, DM & 4 \\
Parkinson's disease, HT & 1 \\
Renal disease, HT & 1 \\
GIS, HT, thyroid, CVS & 1 \\
\hline
\end{tabular}

CVS : cardiovascular system diseases, HT : hypertension, DM : diabetes mellitus, GIS : gastrointestinal system diseases 
was occasional mild pain in score II. These patients also did not need medical support (14, 6.70\%). In score IIIa and b, there was some pain and could be controlled by medical support $(43,20.58 \%)$. We have accepted scores IV and V as failure $(16,7.65 \%)$. In these two groups, the pain was not under complete control with supportive drug therapy.

The results in our study group seemed harmonious with other studies in the literature but were not the best. In order to prevent complications : 1) we avoided to make a lesion to V1 branch. 2) We avoided high temperature and long applications. 3) We avoided RF application for atypical TN. And 4) we closely monitored the quality of the pain, localization and masseter muscle response during stimulation.
We tried to follow up long-term results of the patients. Kaplan-Meier survival analysis method was used for the analysis of the results.

When we checked the results in other series, Son and colleagues $^{28)}$, recurrence rate at the end of 3 rd year in 38 disease series was $29.1 \%$. When we take out the pain control group, our 3 -year recurrence rate was $44.3 \%$. Taha and colleagues ${ }^{30)}$ state that $35 \%$ of patients are out of follow-up during a 14 -year period and that the rate of recurrence was 25\% over this time period. Kanpolat and colleagues ${ }^{14)}$ have followed 719 patients for 5 years and pain control was $57 \%$ in a series of 2138 attempts. In our study at the end of the fifth year, the pain controlled patient rate was $35 \%$.

Table 7. Data for patients with comorbidities

\begin{tabular}{lccccc} 
& $\begin{array}{c}\text { Number of } \\
\text { patients }\end{array}$ & $\begin{array}{c}\text { Number of patients whose pain } \\
\text { have started }\end{array}$ & $\begin{array}{c}\text { Number of controlled patients at } \\
\text { the end of the time margin }\end{array}$ & $\begin{array}{c}\text { Pain control } \\
\text { chance (\%) }\end{array}$ & $\begin{array}{c}\text { Cumulated } \\
\text { chance (\%) }\end{array}$ \\
\hline 1 year & 43 & $2^{*}(10.48 \%) ; 6.86^{\dagger}$ & $41^{*}(32.52 \%) ; 2.21^{\dagger}$ & 95.35 & 95.35 \\
3 years & 41 & $21^{*}(19.96 \%) ; 0.05^{\dagger}$ & $20^{*}(21.04 \%) ; 0.05^{\dagger}$ & 48.78 & 46.51 \\
5 years & 20 & $13^{*}(9.49 \%) ; 1.30^{\dagger}$ & $7^{*}(10.51 \%) ; 1.17^{\dagger}$ & 35.00 & 16.28 \\
\hline
\end{tabular}

*The calculated expected value. ${ }^{\dagger}$ Chi square statistic for the cell only

Table 8. Data for patients with no comorbidities

\begin{tabular}{|c|c|c|c|c|c|}
\hline & $\begin{array}{c}\text { Number of } \\
\text { patients }\end{array}$ & $\begin{array}{c}\text { Number of patients whom have } \\
\text { pain started }\end{array}$ & $\begin{array}{c}\text { Number of controlled patients at } \\
\text { the end of the time margin }\end{array}$ & $\begin{array}{l}\text { Pain control } \\
\text { chance }(\%)\end{array}$ & $\begin{array}{l}\text { Cumulated } \\
\text { chance (\%) }\end{array}$ \\
\hline 1 year & 158 & $47^{*}(38.52 \%) ; 1.87^{\dagger}$ & $111^{*}(119.48 \%) ; 0.60^{\dagger}$ & 70.25 & 70.25 \\
\hline 3 years & 111 & $53^{*}(54.04 \%) ; 0.02^{\dagger}$ & $58^{*}(56.96 \%) ; 0.02^{\dagger}$ & 52.25 & 36.71 \\
\hline 5 years & 58 & $24^{*}(27.51 \%) ; 0.45^{\dagger}$ & $34^{*}(30.49 \%) ; 0.40^{\dagger}$ & 58.62 & 21.52 \\
\hline
\end{tabular}

*The calculated expected value. ${ }^{\dagger}$ Chi square statistic for the cell only

Table 9. Comparison for cumulative pain control between comorbidity group and no comorbidity group

\begin{tabular}{lcccc}
\hline & All patients (\%) & Comorbid patients (\%) & No comorbidity (\%) & $p$-value \\
\hline 1 year & 89.66 & 95.35 & 70.25 & 0.000678 \\
3 years & 55.86 & 46.51 & 36.71 & 0.703894 \\
5 years & 20 & 16.28 & 21.52 & 0.06812 \\
\hline
\end{tabular}

Table 10. Comparison of $p$-values at the end of each year

\begin{tabular}{lcccc} 
& Chi-square statistic & $\boldsymbol{p}$-value & $\begin{array}{c}\text { Yates correction applied } \\
\text { chi-square statistic }\end{array}$ & $\begin{array}{c}\text { Yates correction applied } \\
\boldsymbol{p} \text {-value }\end{array}$ \\
\hline End of 1st year & 11.5473 & 0.000678 & 10.2261 & 0.001385 \\
End of 3rd year & 0.1445 & 0.703894 & 0.0389 & 0.843631 \\
End of 5th year & 3.3278 & 0.06812 & 2.4479 & 0.117685 \\
\hline
\end{tabular}




\section{TN and comorbities}

Of the 156 patients who underwent intervention, 45 (28.85\%) had another disease. Cardiovascular system diseases and hypertension $(n=23,14.74 \%)$ were the most common comorbidities in all patients. This was followed by MS $(n=5$, $3.20 \%$ ), diabetes mellitus ( $n=3,1.92 \%$ ), and thyroid diseases $(n=3,1.92 \%)$ (Table 6). In particular, the etiological linkage of hypertension, MS and diabetes mellitus to TN has been discussed in various studies $3,16,23,26,34,38)$.

When the patients with known cormorbidites such as hypertensive disease, diabetes mellitus, MS, and Parkinson's disease are separated into a group and cumulative pain rates were compared to the group with no known comorbidities, the group with comorbidites had a higher rate of cumulated pain control at the first year as high as $95.35 \%$ compared to the patients with no comorbidites group of 70.25\% (Tables 7-10). The other interesting finding was that the pain control chance between the years 3 and 5 for the patients with no cormobidites group was $58.62 \%$. In this period, pain control rate decreased to $35.00 \%$ in the patient group with comorbidities (Fig. 4).

If the rates for pain control for all patients are taken as expected for the $p$ value for the first-year comorbidities and no comorbidities patient group is calculated the result comes 0.000678 which is considerably significant if a $p$-values below 0.05 is taken as significant. However, when the groups are compared at the end of the third year and fifth year, the $p$-values calculated to be above 0.05 . With the rates of each group is falling to same values at the long term, having a higher rate of control for the first year in the patients with the comorbidities group raises many questions, primarily if this finding is a statistical coincidence, and second what are the possible mecha-

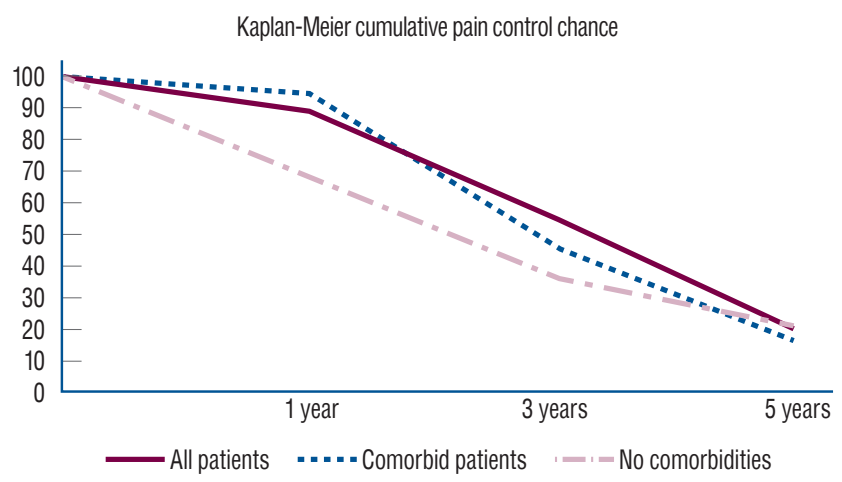

Fig. 4. Comparison of the cumulative pain control chances. nisms causing the difference in the pain control distribution. To check if this was a statistical coincidence despite the calculated $p$-value, Yates correction has been applied as well and the result still fell below 0.05 (0.001385). Yates correction applied results have been reported at Table 10 (Tables 7-10). Such higher control rate for the first year control may have a link to the etiology of disease itself. Since the etiology of the disease is not fully understand the comorbidities reported may have a link to the etiology and these etiologies linked with the comorbidities may respond better to the treatment. The other explanation could be the patient bias. The patients with the comorbidities also include patients who are not able to go into general anesthesia and know this treatment is the final option for them, which may lead them to a somewhat increased tolerance $^{17)}$. It is certain that further studies documenting the patients and their accompanying comorbidities are needed to further explore this deviation.

\section{Analysis of complications}

Facial hypoesthesia developed in all the patients in the first 3-level group. This hypoesthesia was defined as "not disturbing and not troublesome". Donnet and colleagues ${ }^{5)}$ declare that pain relief is obtained at the "cost" of trigeminal hypoesthesia, which ideally is purely thermoalgic but also includes an almost inevitable tactile hypoesthesia or facial numbness. This situation has already been explained to all patients before the intervention.

In three of the patients, sensory changes occurred in a disturbing manner (1.43\%). In the series of Son and colleagues ${ }^{28)}$, one patient reported an occasional and moderate disturbance $(12.5 \%)$, and one patient reported a frequent and severe disturbance (12.5\%).

Masseter muscle weakness was observed in five patients (2.39\%). Broggi and colleagues ${ }^{2)}$ reported 105 cases (10.5\%) of masseter weakness with minor chewing impairment. Son et al. ${ }^{28)}$ described pterygoid or masseter muscle weakness in six patients (15.8\%) after RFT.

Corneal hypoesthesia and anesthesia developed in 3.35\% of our patients. In the Broggi et al. ${ }^{2)}$ 's results, there was a decrease in corneal reflex without any damage to the eye in $19.7 \%$ patients. Son et al. ${ }^{28)}$ wrote that there was no keratitis, weakness in the extraocular muscles, and no deficits in other cranial nerves.

Taha and colleagues ${ }^{30)}$ talk about "producing optimum le- 
sion" while explaining their results. According to them, if the analgesia rates were high, the lowest recurrence rates and the highest rates of dysesthesia were observed. During the interventions, we were careful not to exceed 70 degrees centigrade when applying lesions. We can say that this restriction raises our recurrence rate but keeps our dysesthesia rate low.

\section{Limitations of the study}

One of the points that we want to draw attention to in this study is the decrease in the number of patients followed up in the 5 -year period. The main reasons for this were the decrease in the number of patients who came to follow-up in the outpatient clinic and we could not reach them by telephone. We are aware of this shortcoming affects our long-term results and we want to emphasize that it would be appropriate to consider this in our article.

It is also noteworthy that $\mathrm{TN}$ patients with comorbidities in early post-RFT results have higher success rates. First, one of the factors that will affect the causes of this result is the pathophysiology of TN, which is still not fully understood today. Besides, the results we obtained in our study include a heterogeneous patient group. There are wide range of diseases in this group such as hypertension, MS and diabetes mellitus. To explain the reasons for our results, it is necessary to investigate the links of these diseases with TN separately.

\section{CONCLUSION}

In this study, we presented our intervention criteria, surgical technique we use, short- and long-term outcomes, comorbiditites, complications, and reinterventions. Furthermore, we evaluated other articles about the topics we talked about. We aimed to achieve a high and long success rate and a low complication rate throughout our treatment process. To achieve these goals, our main landmarks were : 1) accurate diagnosis, 2) optimum operating room conditions including C-arm, 3) appropriate localization during intervention, 4) appropriate temperature and appropriate time for lesion generation, and 5) repeat intervention in recurrences. Finally, we conclude that percutaneous RFT of the Gasserian ganglion is a safe and effective method in the treatment of TN. However, over time, the effectiveness of the treatment decreases. Nevertheless, the repeatability of this intervention gives it a distinct advantage.

\section{CONFLICTS OF INTEREST}

No potential conflict of interest relevant to this article was reported.

\section{INFORMED CONSENT}

This type of study does not require informed consent.

\section{AUTHOR CONTRIBUTIONS}

\author{
Conceptualization : HBG, MA \\ Data curation : MG, MLU, OES \\ Methodology : HBG \\ Project administration : HBG \\ Visualization : EE \\ Writing - original draft : $\mathrm{HBG}, \mathrm{OMC}, \mathrm{MA}$ \\ Writing - review \& editing: $\mathrm{HBG}, \mathrm{OMC}, \mathrm{EE}$
}

\section{ORCID}

$\begin{array}{ll}\text { Hasan Burak Gunduz } & \text { https://orcid.org/0000-0003-0020-7928 } \\ \text { Orhun Mete Cevik } & \text { https://orcid.org/0000-0001-9898-3807 } \\ \text { Murad Asilturk } & \text { https://orcid.org/0000-0002-9782-0624 } \\ \text { Muslum Gunes } & \text { https://orcid.org/0000-0003-4923-0889 } \\ \text { Mustafa Levent Uysal } & \text { https://orcid.org/0000-0001-5562-6041 } \\ \text { Ozden Erhan Sofuoglu } & \text { https://orcid.org/0000-0003-3787-6500 } \\ \text { Erhan Emel } & \text { https://orcid.org/0000-0002-0584-9164 }\end{array}$

\section{References}

1. Bharti N, Sujith J, Singla N, Panda NB, Bala I : Radiofrequency thermoablation of the Gasserian ganglion versus the peripheral branches of the trigeminal nerve for treatment of trigeminal neuralgia: a randomized, control trial. Pain Physician 22 : 147-154, 2019

2. Broggi $G$, Franzini $A$, Lasio $G$, Giorgi $C$, Servello $D$ : Long-term results of percutaneous retrogasserian thermorhizotomy for "essential" trigeminal neuralgia: considerations in 1000 consecutive patients. Neurosurgery 26 : 783-786; discussion 786-787, 1990

3. Buono N, Thulesius H, Petrazzuoli F, Castelli E, Cambielli M : Postherpetic neuralgia, diabetic neuropathy, and trigeminal neuralgia - chronic peripheral neuropathic pain in 58,480 rural Italian primary care patients. 
J Family Med Prim Care 6 : 110-114, 2017

4. Chen HI, Lee JY : The measurement of pain in patients with trigeminal neuralgia. Clin Neurosurg 57 : 129-133, 2010

5. Donnet A, Simon E, Cuny E, Demarquay G, Ducros A, De Gaalon S, et al. : French guidelines for diagnosis and treatment of classical trigeminal neuralgia (French Headache Society and French Neurosurgical Society). Rev Neurol (Paris) 173 : 131-151, 2017

6. Frank F, Fabrizi AP : Percutaneous surgical treatment of trigeminal neuralgia. Acta Neurochir (Wien) 97 : 128-130, 1989

7. Goel MK, Khanna P, Kishore J : Understanding survival analysis: KaplanMeier estimate. Int J Ayurveda Res 1 : 274-278, 2010

8. Hart MG, Nowell M, Coakham HB : Radiofrequency thermocoagulation for trigeminal neuralgia without intra-operative patient waking. $\mathrm{Br} \mathbf{J}$ Neurosurg 26 : 392-396, 2012

9. Härtel $F$ : Die Leitungsanästhesie und Injections-Behandlung des Ganglion Gasseri und der Trigeminusstämme, ed 1. Berlin : Springer, 1913, pp1-100

10. Hitchon PW, Holland M, Noeller J, Smith MC, Moritani T, Jerath N, et al. : Options in treating trigeminal neuralgia: experience with 195 patients.

Clin Neurol Neurosurg 149 : 166-170, 2016

11. Iwanaga J, Badaloni F, Laws T, Oskouian RJ, Tubbs RS : Anatomic study of extracranial needle trajectory using Hartel technique for percutaneous treatment of trigeminal neuralgia. World Neurosurg 110 : e245e248, 2018

12. Jannetta PJ : Arterial compression of the trigeminal nerve at the pons in patients with trigeminal neuralgia. J Neurosurg 26:Suppl : 159-162, 1967

13. Jannetta PJ : Vascular compression is the cause of trigeminal neuralgia. APS Journal 2 : 217-227, 1993

14. Kanpolat $Y$, Savas A, Bekar A, Berk C : Percutaneous controlled radiofrequency trigeminal rhizotomy for the treatment of idiopathic trigeminal neuralgia: 25-year experience with 1,600 patients. Neurosurgery 48 : 524-532, discussion 532-534, 2001

15. Katusic S, Beard CM, Bergstralh E, Kurland LT : Incidence and clinical features of trigeminal neuralgia, Rochester, Minnesota, 1945-1984. Ann Neurol 27 : 89-95, 1990

16. Krishnan S, Bigder M, Kaufmann AM : Long-term follow-up of multimodality treatment for multiple sclerosis-related trigeminal neuralgia. Acta Neurochir (Wien) $160:$ 135-144, 2018

17. Linton SJ, Shaw WS : Impact of psychological factors in the experience of pain. Phys Ther $91: 700-711,2011$

18. Liu JK, Apfelbaum RI : Treatment of trigeminal neuralgia. Neurosurg Clin N Am 15 : 319-334, 2004

19. Maarbjerg S, Di Stefano G, Bendtsen L, Cruccu G : Trigeminal neuralgia diagnosis and treatment. Cephalalgia 37 : 648-657, 2017

20. Maxwell RE : Clinical diagnosis of trigeminal neuralgia and differential diagnosis of facial pain in Rovit RL, Murali R, Jannetta PJ (eds) : Trigeminal Neuralgia. Baltimore : Williams \& Wilkins, 1990, pp53-77

21. Morris $L$ : Trigeminal neuralgia.: the anatomy of the "Hartel" technique. Lancet 217 : 122-126, 1931

22. Nugent GR : Radiofrequency treatment of trigeminal neuralgia using a cordotomy-type electrode. A method. Neurosurg Clin N Am 8 : 41 52, 1997

23. Pan SL, Yen MF, Chiu YH, Chen LS, Chen HH : Increased risk of trigeminal neuralgia after hypertension: a population-based study. Neurology 77 : 1605-1610, 2011

24. Peris-Celda M, Graziano F, Russo V, Mericle RA, Ulm AJ : Foramen ovale puncture, lesioning accuracy, and avoiding complications: microsurgical anatomy study with clinical implications. J Neurosurg 119 : 1176-1193, 2013

25. Sabalys G, Juodzbalys G, Wang HL : Aetiology and pathogenesis of trigeminal neuralgia: a comprehensive review. J Oral Maxillofac Res 3 : e2, 2013

26. Sandell T, Holmen J, Eide PK : Hypertension in patients with cranial nerve vascular compression syndromes and comparison with a population-based cohort. J Neurosurg 119 : 1302-1308, 2013

27. Siegfried $\mathrm{J}$ : Percutaneous controlled thermocoagulation of gasserian ganglion in trigeminal neuralgia. Experiences with 1000 cases in Samii M, Jannetta PJ (eds) : The Cranial Nerves, ed 1. Berlin : Springer, 1981, pp322-330

28. Son BC, Kim HS, Kim IS, Yang SH, Lee SW : Percutaneous radiofrequency thermocoagulation under fluoroscopic image-guidance for idiopathic trigeminal neuralgia. J Korean Neurosurg Soc 50 : 446-452, 2011

29. Sweet WH, Wepsic JG : Controlled thermocoagulation of trigeminal ganglion and rootlets for differential destruction of pain fibers. 1. Trigeminal neuralgia. J Neurosurg 40 : 143-156, 1974

30. Taha JM, Tew JM Jr, Buncher CR : A prospective 15-year follow up of 154 consecutive patients with trigeminal neuralgia treated by percutaneous stereotactic radiofrequency thermal rhizotomy. J Neurosurg 83 : 989 993, 1995

31. Tatli $M$, Sindou $M$ : Anatomoradiological landmarks for accuracy of radiofrequency thermorhizotomy in the treatment of trigeminal neuralgia. Neurosurgery 63(1 Suppl 1) : ONS129-ONS137; discussion ONS137ONS138, 2008

32. Tew JM Jr, Taha KM : Percutaneous rhizotomy in the treatment of intractable facial pain (trigeminal, glossopharyngeal, and vagal nerves) in Schmidek HH, Sweet WH (eds) : Operative Neurosurgical Techniques: Indications, Methods, and Results, ed 3. Philadelphia: Saunders, 1995, pp1469-1484

33. van Loveren $H$, Tew JM Jr, Keller JT, Nurre MA : A 10-year experience in the treatment of trigeminal neuralgia. Comparison of percutaneous stereotaxic rhizotomy and posterior fossa exploration. J Neurosurg 57 : 757 764,1982

34. Xu Z, Zhang P, Long L, He H, Zhang J, Sun S : Diabetes mellitus in classical trigeminal neuralgia: a predisposing factor for its development. Clin Neurol Neurosurg $151: 70-72,2016$

35. Yoshimasu F, Kurland LT, Elveback LR : Tic douloureux in Rochester, Minnesota 1945-1969. Neurology 22 : 952-956, 1972

36. Zakrzewska JM : Diagnosis and differential diagnosis of trigeminal neuralgia. Clin J Pain 18 : 14-21, 2002

37. Zakrzewska JM, Jassim S, Bulman SJ : A prospective, longitudinal study on patients with trigeminal neuralgia who underwent radiofrequency 
thermocoagulation of the Gasserian ganglion. Pain 79 : 51-58, 1999

38. Zakrzewska JM, Wu J, Brathwaite TS : A systematic review of the management of trigeminal neuralgia in patients with multiple sclerosis.

World Neurosurg 111 : 291-306, 2018
39. Headache Classification Committee of the International Headache Society (IHS) the international classification of headache disorders, 3rd edition. Cephalalgia $38: 1-211,2018$ 